\title{
CORRECTION
}

\section{Correction to: Incidence of hyperkalemia in the emergency department: a 10-year retrospective study}

\author{
Loïc Lemoine $^{1} \cdot$ Quentin Le Bastard $^{1,2} \cdot$ Damien Masson $^{3} \cdot$ François Javaudin $^{1,2} \cdot$ Eric Batard $^{1,2}$. \\ Emmanuel Montassier ${ }^{1,2}$
}

Published online: 9 November 2019

(c) Società Italiana di Medicina Interna (SIMI) 2019

\section{Correction to: Internal and Emergency Medicine https://doi.org/10.1007/s11739-019-02159-4}

In the original publication of the article, the 3rd author name was swapped. The correct author name should read as Damien Masson.

The original article was corrected.

Publisher's Note Springer Nature remains neutral with regard to jurisdictional claims in published maps and institutional affiliations.

The original article can be found online at https://doi.org/10.1007/ s11739-019-02159-4.

\footnotetext{
Emmanuel Montassier

emmanuelmontassier@hotmail.com

1 Department of Emergency Medicine, Nantes University Hospital, CHU Nantes, 44000 Nantes, France

2 MiHAR Lab, Université de Nantes, 44000 Nantes, France

3 Department of Biochemistry, Nantes University Hospital, 44000 Nantes, France
} 